\title{
Próba adaptacji kwestionariusza Self-Complete of Leeds Assessment of Neuropathic Symptoms and Signs dla polskiej populacji
}

\author{
The Self-Complete of Leeds Assessment Neuropathic Symptoms and Signs: an attempt \\ to adapt it for Polish population
}

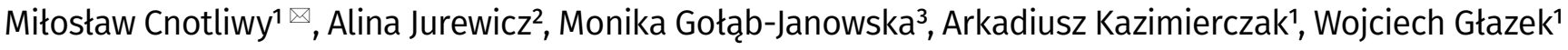 \\ ${ }_{1}^{1}$ Pomorski Uniwersytet Medyczny w Szczecinie, Klinika Chirurgii Naczyniowej, Ogólnej i Angiologii, al. Powstańców Wlkp. 72, 70-111 Szczecin \\ ${ }^{2}$ Pomorski Uniwersytet Medyczny w Szczecinie, Katedra i Klinika Ortopedii, Traumatologii i Onkologii Narządu Ruchu, ul. Unii Lubelskiej 1, 71-252 Szczecin \\ ${ }^{3}$ Pomorski Uniwersytet Medyczny w Szczecinie, Katedra i Klinika Neurologii, ul. Unii Lubelskiej 1, 71-252 Szczecin \\ $\triangle$ mcnotliwy@wp.pl
}

\begin{abstract}
Introduction: The Self-Complete of Leeds Assessment Neuropathic Symptoms and Signs (S-LANSS) questionnaire is a tool for screening patients with neuropathic pain, which can be completed without a physician's assistance. Until now, a Polish version of the S-LANSS has not been available.

The aim of the study was to translate the English version into the Polish language and to validate it for the Polish population. Materials and methods: A total of 101 subjects; 51 with chronic neuropathic pain in the course of different neurological diseases, and 50 patients with osteoarthritis and nociceptive pain were included in the study. All of them completed a version of
\end{abstract}

the S-LANSS questionnaire translated into the Polish language. Test sensitivity and specificity were calculated on the basis of statistical analysis.

Results: The sensitivity of the S-LANSS scale with the cut-off of $\geq 11$ points was $62 \%$, and the specificity was $77 \%$. The estimated area under ROC curve AUC $(95 \% \mathrm{CI})=0.729(0.63-0.809)$. Conclusions: The Polish version of S-LANSS could be used as a tool for screening patients with neuropathic pain. The diagnosis should be confirmed in neurological examination and other appropriate diagnostic methods.

Keywords: neuropathic pain; screening questionnaire.

\begin{abstract}
ABSTRAKT
Wstęp: Kwestionariusz Self-Complete of Leeds Assessment of Neuropathic Symptoms and Signs (S-LANSS) jest testem przesiewowym służącym rozpoznaniu bólu neuropatycznego. Test ten może wykonać chory bez pomocy lekarza.

Celem pracy było przetłumaczenie oryginalnej anglojęzycznej wersji skali S-LANSS na język polski oraz jej walidacja dla polskiej populacji.

Materiały i metody: Do badania włączono 101 chorych: 51 z rozpoznanym przewlekłym bólem neuropatycznym w przebiegu różnych schorzeń neurologicznych i 50 z przewlekłym bólem receptorowym w przebiegu choroby zwyrodnieniowej stawów. Wszyscy samodzielnie wypełnili przetłumaczony na język polski
\end{abstract}

kwestionariusz S-LANSS. W analizie statystycznej zwrócono szczególną uwagę na określenie czułości i swoistości polskojęzycznej wersji kwestionariusza.

Wyniki: Czułość kwestionariusza S-LANSS przy punkcie odcięcia $\geq 11$ wyniosła $62 \%$, a swoistość $77 \%$. Pole pod krzywą ROC, $\operatorname{AUC}(95 \% \mathrm{CI})=0,729(0,63-0,809)$.

Wnioski: Opracowana polskojęzyczna wersja S-LANSS może być użyta do wstępnej diagnozy bólu neuropatycznego. Rozpoznanie musi opierać się na badaniu neurologicznym, uzupełnionym testami neurofizjologicznymi i niezbędnymi badaniami dodatkowymi.

Słowa kluczowe: ból neuropatyczny; kwestionariusz skriningowy.

\section{WSTĘP}

Według zaktualizowanej w 2011 r. definicji ból neuropatyczny jest następstwem uszkodzenia albo choroby obwodowego lub ośrodkowego układu czucia somatycznego [1]. Częstość występowania bólu neuropatycznego (NP) jest trudna do określenia, gdyż ten rodzaj bólu ma różnorodną etiologię i może występować w mieszanych zespołach bólowych. Innym powodem jest brak standaryzowanych oraz rekomendowanych instrumentów do badań epidemiologicznych i przesiewowych w tym zakresie. W 2006 r. Torrance i wsp. wykorzystując kwestionariusz Self-Complete of Leeds Assessment of Neuropathic Symptoms and Signs (S-LANSS), ocenili, że NP dotyczy 8,2\% ogólnej populacji i 17\% chorych z bólem przewlekłym [2]. Skalę S-LANSS stworzyli i walidowali dla populacji angielskiej Bennett i wsp. [3]. Jej zaletą jest możliwość wykonania testu przez samego chorego oraz łatwość interpretacji wyników. Cechy te powodują, że narzędzie to może być przydatne dla lekarzy w praktyce 
ambulatoryjnej przy wstępnej ocenie rodzaju bólu i jego leczeniu. Skala S-LANSS nie była dotychczas dostępna w polskiej wersji językowej.

Za cel pracy przyjęto przetłumaczenie oryginalnej anglojęzycznej wersji kwestionariusza na język polski oraz jego walidacja dla polskiej populacji.

\section{MATERIAtY I METODY}

Po uzyskaniu akceptacji Komisji Bioetycznej przy Pomorskim Uniwersytecie Medycznym w Szczecinie na przeprowadzenie badania (uchwała nr KB-0012/81/13) zwrócono się pocztą elektroniczną do autora kwestionariusza Michaela Bennetta o udzielenie zgody na przetłumaczenie jego wersji na język polski i użycie w badaniu klinicznym. Zgodę taką otrzymano.

Tłumaczenia dokonali niezależnie od siebie: rodowity Anglik władający językiem polskim, Polak mieszkający w Wielkiej Brytanii posługujący się biegle językiem angielskim oraz polski lektor języka angielskiego. Ostateczną wersję ustalono po konsultacji zespołu badaczy z kolejnym lektorem języka angielskiego (załącznik 1).

Kwestionariusz S-LANSS zawiera 5 pytań i 2 sugerowane odpowiedzi na każde z nich, opisujące odczuwany ból, a także 2 testy, które pacjent wykonuje samodzielnie, dotyczące czucia somatycznego i podatności na allodynię. Każdy z elementów

\section{Załącznik 1}

\section{S-LANSS PAIN SCORE}

Inicjały Płeć Wiek Data

Wypełnienie tego kwestionariusza pomoże nam w rozpoznaniu rodzaju bólu, na który Pani/Pan cierpi. To z kolei będzie pomocne w podjęciu decyzji, w jaki sposób najskuteczniej będzie można zwalczać ten ból.

Proszę zaznaczyć na rysunku poniżej, w którym miejscu odczuwa Pani/Pan ból. Jeżeli ból dotyczy więcej niż jednego miejsca, proszę wskazać tylko to, gdzie ból jest najbardziej dokuczliwy.
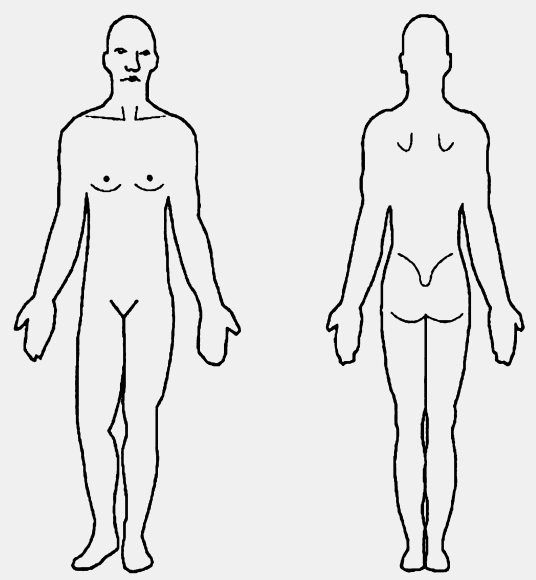

Na skali poniżej proszę wskazać natężenie bólu w ostatnim tygodniu (w miejscu, które było zaznaczone na rysunku powyżej). „0" oznacza brak bólu, „10” oznacza ból najsilniejszy z możliwych.

$\begin{array}{lllllllllll}0 & 1 & 2 & 3 & 4 & 5 & 6 & 7 & 8 & 9 & 10\end{array}$

Na drugiej stronie znajdzie Pani/Pan 7 pytań dotyczących odczuwanego bólu (w miejscu zaznaczonym poprzednio na rysunku).

Dotyczą one bólu odczuwanego w ostatnim tygodniu (w miejscu zaznaczonym poprzednio na rysunku). Proszę zakreślić odpowiedź, która najlepiej opisuje odczuwany ból.

Proszę odwrócić stronę.
1. Czy w bolesnej okolicy odczuwasz mrowienie lub kłucie, czy masz wrażenie, jakby były tam szpilki, igły?

a) NIE Nie mam takiego wrażenia (0)

b) TAK Mam takie wrażenie (5)

2. Czy skóra nad bolesnym miejscem zmienia kolor (czy pojawiają się plamy lub zaczerwienienie), kiedy ból staje się szczególnie dokuczliwy?

a) NIE Zabarwienie skóry nie zmienia się (0)

b) TAK Zauważyłem, że gdy pojawia się ból, skóra wygląda inaczej niż normalnie (5)

3. Czy ból powoduje, że skóra nad tym miejscem staje się szczególnie czuła na dotyk, czy delikatne uderzenie, głaskanie wywołuje nieprzyjemne wrażenie?

a) NIE Ból nie powoduje, że skóra staje się bardziej wrażliwa na dotyk (0)

b) TAK Skóra w tej okolicy jest szczególnie wrażliwa na dotyk (3)

4. Czy ból pojawia się nagle i wybucha bez wyraźnego powodu, nawet kiedy jesteś spokojny? Czy ból możesz określić jako rażenie prądem, uderzenie?

a) NIE Nie odczuwam bólu w ten sposób (0)

b) TAK Mam często takie wrażenie (2)

5. Czy na skórze w bolesnej okolicy masz uczucie gorąca, pieczenia?

a) NIE Nie mam piekącego bólu (0)

b) TAK Często mam piekący ból (1)

6. Delikatnie pocieraj skórę nad bolesnym miejscem wskazującym palcem, a następnie miejsce niebolesne (na przykład skórę obok tego miejsca lub po przeciwnej stronie). Co odczuwasz w bolesnej okolicy?

a) Czucie w bolesnej okolicy nie różni się od zdrowej (0)

b) Czuję dyskomfort, jakby ukłucie szpilką, igłą, mrowienie (5)

7. Czubkiem palca delikatnie naciśnij bolesne miejsce, a następnie miejsce niebolesne (tak jak w poprzednim zadaniu). Co odczuwasz w bolesnej okolicy?

a) W bolesnym i zdrowym miejscu wrażenie jest takie samo (0)

b) Bolesne miejsce jest bardziej wrażliwe i tkliwe w porównaniu ze zdrowym (3)

Wynik 12 punktów lub więcej oznacza, że ból ma pochodzenie głównie neuropatyczne. 
jest punktowany. Wynik $\geq 12$ pkt wskazuje na duże prawdopodobieństwo bólu typu neuropatycznego. Do kwestionariusza dołączona jest też numeryczna skala oceny natężenia bólu (NPS), gdzie o oznacza brak bólu, a 10 ból najsilniejszy.

Przetłumaczoną wersję, w celu określenia zrozumiałości zawartych w kwestionariuszu pytań i poleceń oraz czasu potrzebnego na wypełnienie formularza, poddano testowi w grupie 10 chorych skarżących się na różne dolegliwości bólowe; 9 pacjentów odpowiedziało, że kwestionariusz jest zrozumiały, a 1, że pytania nie są dość jasne. Czas wypełnienia kwestionariusza wynosił 7-10 min.

Do badania włączono 101 chorych, od których uzyskano świadomą zgodę: 51 chorych z rozpoznanym przewlekłym bólem neuropatycznym (NeuP) pochodziło z Poradni Neurologicznej Samodzielnego Publicznego Szpitala Klinicznego nr 1 w Szczecinie (SPSK nr 1). Grupa ta obejmowała: 11 chorych z polineuropatią cukrzycową, 5 z zespołem cieśni nadgarstka, $5 \mathrm{z}$ uszkodzeniem pourazowym nerwu łokciowego, $5 \mathrm{z}$ polineuropatią dziedziczną, $4 \mathrm{z}$ przewlekłą zapalną poliradikulopatią demielinizacyjną, $4 \mathrm{z}$ bólem poudarowym ośrodkowym, 3 ze stopą cukrzycową neuropatyczną, 3 z neuralgią nerwu trójdzielnego, 3 z neuropatią popółpaśćcową, 2 z bólem fantomowym, $1 \mathrm{z}$ neuralgią nerwu potylicznego, $1 \mathrm{z}$ pourazowym uszkodzeniem splotu barkowego, $1 \mathrm{z}$ polineuropatią toksyczną, $1 \mathrm{z}$ zawałem rdzenia kręgowego, $1 \mathrm{z}$ chorobą Charcota-MariegoTootha oraz 1 z zespołem Guilliana-Barrego. Kwestionariusz był wypełniany podczas planowej wizyty w poradni.

Drugą grupę, 50 chorych, stanowili pacjenci z przewlekłym bólem receptorowym (NocP) leczeni w Klinice Ortopedii SPSK $\mathrm{nr} 1 \mathrm{w}$ Szczecinie z powodu choroby zwyrodnieniowej stawów kolanowych (24) i biodrowych (26), u których nie stwierdzono współistniejących schorzeń neurologicznych. Kwestionariusz wypełniany był podczas pobytu w klinice przed planowanym leczeniem operacyjnym.

\section{ANALIZA STATYSTYCZNA}

Parametry opisowe (średnia, odchylenie standardowe) były obliczane dla skali S-LANSS i NPS. Test U Manna-Whitneya użyto do porównania pomiędzy grupami NeuP i NocP z powodu nienormalnego rozkładu zmiennych. Zmienne policzalne porównano dokładnym testem Fishera. Korelację pomiędzy skalami S-LANSS i NPS zbadano przy użyciu analizy regresji. Czułość, specyficzność oraz punkty odcięcia zostały obliczone przy użyciu analizy ROC dla wartości skali S-LANSS. Za istotne statystycznie różnice uznawano wartości p < 0,05. Analizę przeprowadzono przy użyciu programów Statistica.pl wersji 5.0 Statsoft oraz MedCalc wersja 15.1.

\section{WYNIKI}

Nie stwierdzono istotnych statystycznie różnic między porównywanymi grupami, jeśli chodzi o płeć badanych $(\mathrm{p}=0,174)$ i wiek $(p=0,522)$.

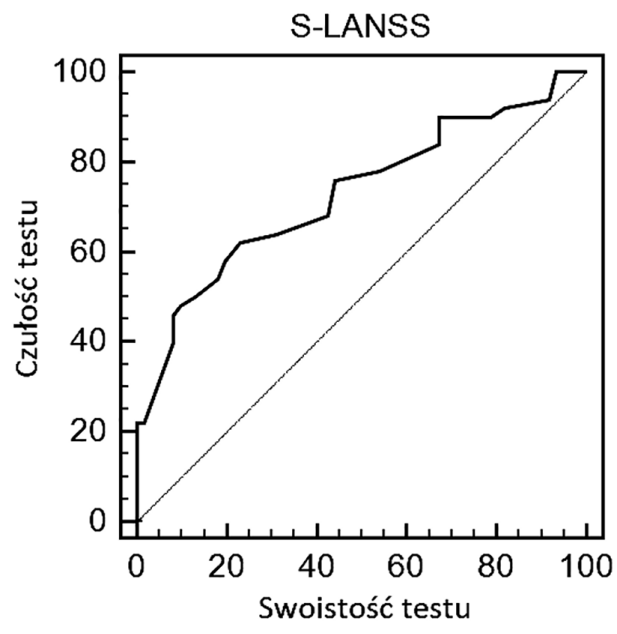

RYCINA 1. Krzywa ROC (receiver operating characteristics) dla polskojęzycznej wersji kwestionariusza S-LANSS

Średnia wartość określająca natężenie bólu w skali NPS dla grupy NeuP wyniosła 6 pkt, przy odchyleniu standardowym (SD/\%) 2,27. Dla grupy NocP 7,39 (SD/\% 1,88). Różnica była istotna statystycznie ( $p=0,00095)$.

Średnia wartość punktowa skali S-LANSS dla grupy NeuP wyniosła 13,63 (SD/\% 7,35), dla grupy NocP 8,574 (SD/\% 5,13). Różnica była istotna statystycznie, $p=0,00028$.

Nie było korelacji $\left(\mathrm{r}^{2}=0,002 ; \mathrm{p}=0,269\right)$ pomiędzy wartościami skali S-LANSS i NPS w całej zsumowanej grupie (NeuP + NocP). Nie zaobserwowano jej również w podgrupach. Dla grupy NeuP wartości te wyniosły $r^{2}=0,0007 ; p=0,851$; a dla grupy NocP $-\mathrm{r}^{2}=0,015 ; \mathrm{p}=0,345$.

Punkt odcięcia dla rozpoznania bólu neuropatycznego na podstawie S-LANSS wyniósł $\geq 11$, czułość testu $62 \%$, specyficzność 77\% (AUC 0,729; p = 0,0001; 95\% CI 0,637-0,809) - rycina 1.

\section{DYSKUSJA}

Spośród wielu skal służących do wstępnej oceny rodzaju bólu najbardziej rozpowszechnione są: McGill Pain Questionnaire, Neuropathic Pain Questionnaire, Pain DETECT, Douleur Neuropathique 4 oraz Leeds Assessment of Neuropathic Symptoms and Signs (LANSS) [1,4]. Ból jest odczuciem subiektywnym, więc różnicowanie pomiędzy bólem neuropatycznym a receptorowym na podstawie deskryptorów werbalnych, może być niewystarczająco precyzyjne. Wymienione narzędzia przesiewowe służące do identyfikacji NP, szczególnie jeśli są stosowane przez lekarzy niebędących neurologami, nigdy nie mogą zastępować dokładnego badania klinicznego, w tym jakościowych testów czucia, badań neurofizjologicznych itd. [4]. Kwestionariusze skriningowe, zwłaszcza używane w różnych wersjach językowych i adaptowane dla różnych kulturowo populacji, mają też istotne naturalne ograniczenia [5, 6].

Skala LANSS i jej modyfikacja S-LANSS doczekały się licznych tłumaczeń, m.in. na język hiszpański [7], portugalski [8], grecki [9], turecki [10, 11], arabski [12] oraz koreański [13].

W opracowanej przez autorów wersji kwestionariusza S-LANSS czułość testu przy wyliczonym punkcie odcięcia $\geq 11$ 
wyniosła $62 \%$, a swoistość $77 \%$. Wynik ten jest niższy od wartości podawanych przez innych autorów: czułość 72,3\%, swoistość 80,4\% [11] oraz odpowiednio 86,21\% i 95,24\% [9], 98\% i $97 \% \%$ [10]. W oryginalnej wersji angielskiej przy punkcie odcięcia $\geq 12$ pkt czułość wynosiła $74 \%$, a swoistość $76 \%$ [3]. Takie rozbieżności mogą wynikać m.in. z liczebności badanych grup. W materiale własnym badano 101 pacjentów, a w innych ośrodkach włączano 100-200 chorych [3, 9, 10, 11].

W przedstawionej pracy zwrócono uwagę na dużą różnorodność schorzeń neurologicznych u chorych w grupie z bólem neuropatycznym. Pomimo tego, że badanie trwało blisko 3 lata, nie udało się ujednolicić tej grupy. Ból w przebiegu choroby zwyrodnieniowej stawów kończyn jest bólem nocyceptywnym [14]. Ta grupa chorych jest więc jednorodna. Na uwagę zasługuje spostrzeżenie, że średnia wartość określająca natężenie bólu w skali NPS była niższa w grupie chorych z bólem neuropatycznym, czym różni się od wyników uzyskanych przez innych autorów [7]. Ze względów organizacyjnych niemożliwe było przeprowadzenie ponownego badania „test-retest” u tych samych chorych. Nie można wykluczyć też błędów lingwistycznych. Przykładem różnic wynikających z metodyki tłumaczenia może być porównanie tłumaczeń pierwszych 5 pytań w niniejszej publikacji z inną polską pracą [15].

Walka z bólem neuropatycznym różni się znacząco od leczenia bólu nocyceptywnego [16]. Zastosowanie takiego narzędzia jak S-LANSS, zwłaszcza w praktyce ambulatoryjnej, może wpłynąć zarówno na wybór rodzaju leczenia, jak i jego skuteczność.

\section{WNIOSKI}

Przedstawiona polskojęzyczna wersja S-LANSS może być użyta do wstępnej diagnozy bólu neuropatycznego. Rozpoznanie musi opierać się na badaniu neurologicznym, uzupełnionym testami neurofizjologicznymi i niezbędnymi badaniami dodatkowymi.

\section{PIŚMIENNICTWO}

1. Haanpaa M, Attal N, Backonja M, Baron R, Bennett M, Bouhassira D, et al. NeuPSIG guidelines on neuropathic pain assessment. Pain 2011;152(1):14-27.
2. Torrance N, Smith BH, Bennett MI, Lee AJ. The epidemiology of chronic pain of predominantly neuropathic origin. Results from a general population survey. J Pain 2006;7(4):281-9.

3. Bennett MI, Smith BH, Torrance N, Potter J. The S-LANSS score for identifying pain predominantly neuropathic origin: validation for use in clinical and postal research. J Pain 2005;6(3):149-58.

4. Croccu G, Sommer C, Anand P, Attal N, Baron R, Garcia-Larrea L, et al. EFNS guidelines on neuropathic pain assessment: revised 2009. Eur J Neurol 2010;17(8):1010-8.

5. Mathieson S, Maher CG, Terwee CB, Folly de Campos T, Lin CW. Neuropathic pain screening questionnaires have limited measurement properties. A systematic review. J Clin Epidemiol 2015;68(8):957-66.

6. Attal N. Screening tool for neuropathic pain: are they adaptable in different languages and cultures? Pain Med 2010;11(7):985-6.

7. Perez C, Galvez R, Insausti J, Bennett M, Ruiz M, Rejas J. Linguistic adaptation and Spanish validation of the LANSS (Leeds Assessment of Neuropathic Symptoms and Signs) scale for the diagnosis of neuropathic pain. Med Clin (Barc). 2006;127(13):485-91.

8. Schestatsky P, Felix-Torres V, Chaves MLF, Camara-Ehlers B, Mucenic T, Caumo W, et al. Brazilian Portuguese validation of the Leeds Assessment of Neuropathic Symptoms and Signs for patients with chronic pain. Pain Medicine 2011;12(10):1544-50.

9. Batistaki C, Lyrakos G, Drachtidi K, Stamatiou G, Kitsou MC, Kostopanagiotou G. Translation, cultural adaptation, and validation of Leeds Assessment of Neuropathic Symptoms and Signs (LANSS) and Self-Complete of Leeds Assessment of Neuropathic Symptoms and Signs (S-LANSS) questionnaires into the Greek language. Pain Practice 2016;16(5):552-64.

10. Turkel Y, Turker H, Demir IA, Baytrak AO, Onar MK. Validation of self report of Leeds Assessment of Neuropathic Symptoms and Signs score for identification of neuropathic pain in patients from northern Turkey. Adv Clin Exp Med 2014;23(4):599-603.

11. Koc R, Erdemoglu AK. Validity and reliability of the Turkish Self-administered Leeds Assessment of Neuropathic Symptoms and Signs (S-LANSS) Questionnaire. Pain Med 2010;11(7):1107-14.

12. Elzahaf RA, Tashani OA, Unsworth BA, Johnson MI. Translation and linguistic validation of the self-completed Leeds Assessment of Neuropathic Symptoms and Signs (S-LANSS) scale for use in a Libyan population. Pain Practice 2012;13(3):198-205.

13. Cho SI, Lee CH, Park GH, Park CW, Kim HO. Use of S-LANSS, a tool for screening neuropathic pain, for predicting post herpetic neuralgia in patients after acute herpes zoster events. A single-center, 12-months, prospective cohort study. J Pain 2014;15(2):149-56.

14. Ordeberg G. Characterisation of joint pain in human OA. In: Osteoarthric joint pain. Chichester: John Wiley \& Sons; 2004. p. 105-21

15. Bisaga W, Dorazil M, Dobrogowski J, Wordliczek J. Porównanie przydatności wybranych skal oceny bólu neuropatycznego u pacjentów z przewlekłymi zespołami bólowymi: krótkie doniesienie. Med Pal Prakt 2011;5:22-6.

16. Dworkin RH, O'Connor AB, Audette J, Baron R, Gourlay GK, Haanpaa ML, et al. Recommendations for the pharmacological management of neuropathic pain: an overview and literature update. Mayo Clin Proc 2010;85 (suppl): S3-S14. 